\title{
Investigation of Adsorption Characteristics of an Engineered Adsorbent for Removal of Hexavalent Chromium from Aqueous Solutions
}

\author{
Yogesh C. Sharma, Elham Jalilnejad, and Sofia Yarusova
}

\begin{abstract}
Application of iron oxide loaded sand (IOLRS) for the removal of hexavalent chromium has been investigated. The noral ilica sand was used in the experiments. IOLRS was characterized by XRD, and FTIR to investigate its specific characteristics. Particle size was found to be in the range 2.5 to $200 \mu \mathrm{m}$. Removal efficiency of adsorbent for $\operatorname{Cr}(\mathrm{VI})$ was determined for batch adsorption experiments. Effect of various important parameters such as concentration, $\mathrm{pH}$, temperature and adsorbent dose on the removal of $\mathrm{Cr}(\mathrm{VI})$ was investigated. The removal of $\mathrm{Cr}$ (VI) was better in acidic $\mathrm{pH}$ range. The removal increased from 65 to $71.66 \%$ by increasing temperature from 25 to $450 \mathrm{C}$ showing the process of removal to be endothermic. Kinetic studies revealed that removal process is governed by pseudo first order kinetic model. Intraparticle diffusion was not found to be rate limiting step in removal process. Langmuir and Freundlich adsorption capacity was found to be 0.36 and $0.18 \mathrm{mg} / \mathrm{g}$ respectively at $450 \mathrm{C}$. Various thermodynamic parameters viz. $\Delta \mathrm{G}^{0}, \Delta \mathrm{H}^{0}$ and $\Delta \mathrm{S}^{0}$ were determined. Value of $\Delta G^{0}$ was found to be negative which confirms the feasibility of process while positive values of $\Delta \mathbf{H}^{0}$ further confirm endothermic nature of the process. Present study revealed that Iron oxide loaded riverbed sand (IOLRS) can be used as an alternative for the otherwise 'more expensive' adsorbents and resultant data may help in designing treatment plants for the $\mathrm{Cr}(\mathrm{VI})$ rich effluents.
\end{abstract}

Index Terms - $\mathrm{Cr}(\mathrm{VI})$, adsorption, removal, riverbed sand, kinetics, isotherm.

\section{INTRODUCTION}

Chromium and their compounds have widespread applications in various industries such as electroplating, textile dyeing, leather tanning, steel fabrication and wood preservative treatment industries [1], [2]. These industries discharge large amount of chromium, especially into the aquatic environment [3]-[5]. Trivalent and hexavalent oxidation states of chromium are important from environmental viewpoint. $\mathrm{Cr}$ (III) is essential in glucose metabolism and $\mathrm{Cr}$ (VI) is more soluble than $\mathrm{Cr}$ (III) and therefore it is easily available for biological uptake. The phase

Manuscript received March 16, 2016; revised October 13, 2016.

Yogesh C. Sharma is with Department of Chemistry, Indian Institute of Technology (BHU) Varanasi, Varanasi 221005, India (e-mail: ysharma.apc@iitbhu.ac.in).

Elham Jalilnejad is with the Department of Chemical Engineering, Department of Chemical Engineering, Urmia University of Technology, Iran (e-mail: elham.jalilnejad@ gmail.com).

Sofia Yarusova is with Institute of Chemistry, Far-Eastern Branch of Russian Academy of Sciences; 690022, Russian Federation, Vladivostok, Prospekt 100-letya Vladivostoka, 159; Vladivostok State University of Economy and Service; 690014, Russian Federation, Vladivostok, Gogolya street, 41. that will be present in aqueous solutions depends on solution pH. $\mathrm{Cr}(\mathrm{VI})$ can be present as chromate $\left(\mathrm{CrO}_{4}{ }^{2-}\right)$, hydrogen chromate $\left(\mathrm{HCrO}_{4}^{-}\right)$or dichromate $\left(\mathrm{Cr}_{2} \mathrm{O}_{7}{ }^{2-}\right)$ in aqueous solutions [2]. $\mathrm{Cr}(\mathrm{VI})$ is known to be carcinogenic and mutagenic and it is also reported to pose skin ulceration, nausea, liver damage, and pulmonary congestion, vomiting, and severe diarrhea [1], [6]. These facts make it necessary to restrict $\mathrm{Cr}(\mathrm{VI})$ from entering wastewaters and finally the aquatic sources. The maximum concentration limit of $\mathrm{Cr}(\mathrm{VI})$ for discharge into inland surface waters is $0.1 \mathrm{mg} / \mathrm{L}$ and in potable water it is $0.05 \mathrm{mg} / \mathrm{L}$ (WHO, 1993) [7]. Variety of treatment technologies viz. chemical precipitation, coagulation, solvent extraction, membrane separation, reverse osmosis, ultra filtration, electrochemical deposition, ion exchange and adsorption can be used for the treatment of water and wastewater. But most of these available processes have various disadvantages including incomplete metal removal, requirements for expensive equipment, generation of toxic sludge etc. [8]-[11]. Among these methods, adsorption is very popular due to its simplicity as it is one of the most economically favorable, reliable and easy method for the removal of toxic heavy metals from water and wastewater even at trace level [12], [13]. Studies on the removal of metallic pollutants by low-cost and naturally available adsorbents like wool, saw dust, used tiers, seaweed, dead fungal biomass, sand, clay, wollastonite and dolomite have been conducted recently [12]. The objective of this study is to synthesize an effective adsorbent capable yet economically viable for the removal of $\mathrm{Cr}$ from aqueous solutions. Iron oxide loaded riverbed sand (IOLRS) has been prepared in laboratory and then it has been applied as adsorbent material for the removal of hexavalent chromium from aqueous solutions. The studies have been conducted for optimization of various parameters like contact time, initial adsorbate concentration, adsorbent dose, $\mathrm{pH}$ and temperature. Kinetic studies for removal of $\mathrm{Cr}$ have been carried out. Equilibrium data have been analyzed by different isotherms viz. Langmuir, and Freundlich isotherm models. Thermodynamics studies were also carried out.

\section{MATERIALS AND METHODS}

\section{A. Preparation of Adsorbent}

For present study, natural clay (NC) samples were collected from shallow waters nearer from the bank of river Ganges, Varanasi, India. The NC samples were stored in properly cleaned polythene bags. NC was washed with 
distilled water to remove impurities and then dried in a hot air oven at $105^{\circ} \mathrm{C}$ overnight. Particle size of adsorbent samples was maintained using different sieves. After maintaining the particle size, the NC was modified by iron oxide for enhancement of adsorption efficiency. For this purpose, solution of Ferric and Ferrous chloride (molar ratio 2:1) were prepared by dissolving Ferric and Ferrous chloride into distilled water. Dried clay particles have been added slowly into the solution of Ferric and Ferrous chloride by continuous stirring on magnetic stirrer. Chemical precipitation was achieved by adding $\mathrm{NH}_{4} \mathrm{OH}$ under vigorous stirring at room temperature. During the whole reaction process, $\mathrm{pH}$ of the solution was maintained at 10 . After completion of reaction, resultant precipitates were washed several times with distilled water, and then finally dried in oven at $50^{\circ} \mathrm{C}$ for $24 \mathrm{~h}$. Iron oxide loaded riverbed sand (IOLRS) was characterized by XRD (RIGAKU, MINIFLEX II, Desktop X- Ray Diffractometer, Japan) FTIR(Varian 1000 FT-IR, Scimitar Series ) and SEM.

\section{B. Adsorption Studies}

Stock solution of $\mathrm{Cr}(\mathrm{VI})$ was prepared by dissolving known amount of potassium dichromate in $1000 \mathrm{~mL}$ of double distilled water. Working solutions for the adsorption experiments were prepared by proper dilution of stock solution. Batch adsorption experiments were conducted by taking $50 \mathrm{ml}$ of $\mathrm{Cr}$ (VI) solution in $125 \mathrm{ml}$ of glass caped reagent bottles at desired $\mathrm{pH}$ value, temperature, contact time, dose and adsorbate concentration. The solutions were agitated at $100 \mathrm{rpm}$ on a shaking thermostat at $25^{\circ} \mathrm{C}( \pm 0.5)$. Ionic strength of the chromium solutions was maintained at $1.0 \times 10^{-2} \mathrm{M} \mathrm{NaClO}_{4}$. The adsorbent was separated from the aqueous solutions by centrifugation after the equilibrium time (Remi 24, New Delhi, India). Residual concentrations of $\mathrm{Cr}(\mathrm{VI})$ in aqueous solutions were determined by Atomic Absorption Spectrophotometer (AA 7000,Shimadzu, Japan). All the removal experiments were carried out in duplicate for accuracy of results. The percentage removal of $\mathrm{Cr}(\mathrm{VI})$ in aqueous solutions and the amount of $\mathrm{Cr}$ adsorbed was calculated using expressions as reported elsewhere [12].

In the present investigation, desorption studies were also carried out in batches. For desorption studies, $\mathrm{Cr}(\mathrm{VI})$ adsorbed on IOLRS was first washed by double distilled water to remove the un-adsorbed $\mathrm{Cr}(\mathrm{VI})$ ions that are loosely adhered on the adsorbent surface. Desorption studies was carried out at different $\mathrm{pH}$ at $4,5,6,7,8,9,10,11$ and 12, shaking rate of $100 \mathrm{rpm}$, and $30^{\circ} \mathrm{C}$. Exhausted adsorbent, $0.50 \mathrm{~g} / 50 \mathrm{ml}$,was then mixed with distilled water of different $\mathrm{pH}$. The residual concentrations of $\mathrm{Cr}$ in aliquot were determined by AAS.

\section{RESULTS AND DISCUSSION}

\section{A. Characterization of the Adsorbent}

XRD of Iron oxide loaded riverbed sand (IOLRS) was carried out and has been shown in Fig. 1. XRD data of adsorbent material confirms the presence of $\mathrm{SiO}_{2}$, Goethite and Hametite. The XRD data of adsorbent material was compared from the standard XRD data of $\mathrm{SiO}_{2}$, Goethite and
Hametite (Fig. 1).

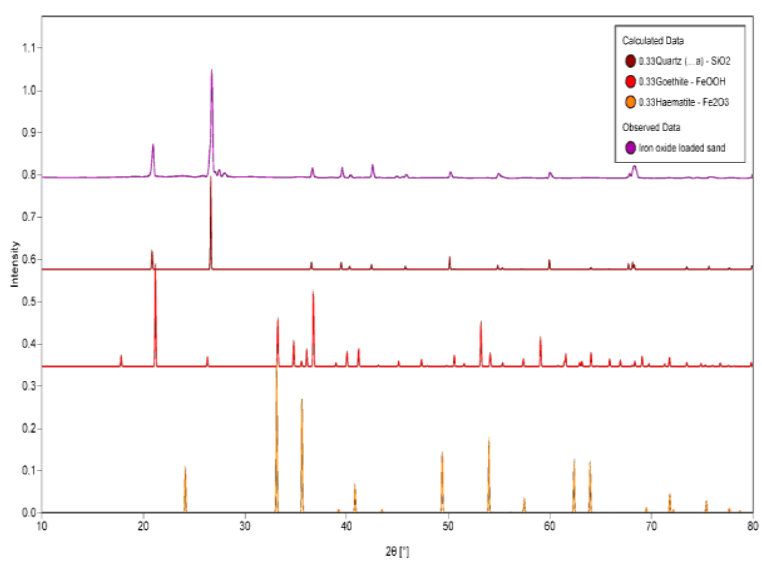

Fig. 1. XRD of IOLRS.

It can be also concluded from this data that loading of iron oxide is in the form of Goethite and Hametite. It also confirms the crystallinity of synthesized adsorbent. In any adsorption process, the FTIR spectrum of adsorbent material before and after adsorption clarifies important points regarding surface groups' analysis and changes in adsorbent surface characteristics during adsorption. Fig. 2 depicts the FT-IR spectra of the IOLRS before and after adsorption process. The absorption peaks at $3442 \mathrm{~cm}^{-1}$ is associated with the stretching vibration of hydroxyl groups. Absorption peaks in the range of 400 to $1000 \mathrm{~cm}^{-1}$ are related with the metal-oxygen vibration. Peaks at 1626 and $1620 \mathrm{~cm}^{-1}$ in IOLRS before and after adsorption is due to bending of water molecules. The new absorption peak at $2929 \mathrm{~cm}^{-1}$ may be due to the bond formation between $\mathrm{Cr}(\mathrm{VI})$ and adsorbent.

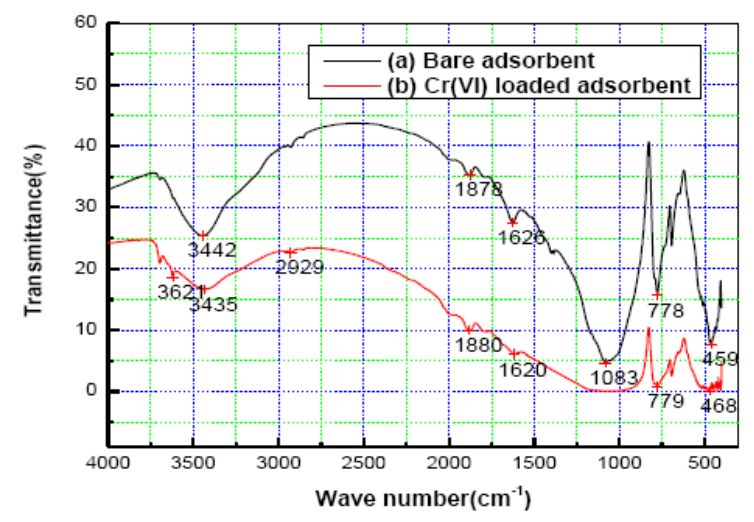

Fig. 2. FTIR of IOLRS.



Fig. 3. Effect of contact time and concentration on the removal of $\mathrm{Cr}$ (VI) by adsorption on IOLRS 


\section{B. Effect of Contact Time and Initial Concentration on the Removal}

Adsorbate concentration has significant effect on any removal process. The effect of initial $\mathrm{Cr}(\mathrm{VI})$ concentration on $\mathrm{Cr}(\mathrm{VI})$ removal was investigated in the range of 6.8 to $13.6 \times 10^{-3} \mathrm{~mol} / \mathrm{L}$. The effect of contact time and concentration on the adsorption of $\mathrm{Cr}(\mathrm{VI})$ at different initial concentrations is represented in Fig. 3. It is clear from that removal is rapid in initial stages and then decreases slowly till equilibrium is attained (Fig. 3). After attainment of equilibrium, there is no significant change in the rate of removal of $\mathrm{Cr}(\mathrm{VI})$. This trend may be due to presence of greater number of available adsorption sites at the initial stages of adsorption. In present study, equilibrium time was found to be $90 \mathrm{~min}$. It is clear from the Fig. 3 that by increasing initial concentration, removal decreased from 65 to $50.83 \%$.

\section{Kinetic Study}

Adsorption kinetics depends on the adsorbate-adsorbent interaction and other operating conditions. In present study, batch sorption kinetics of $\mathrm{Cr}(\mathrm{VI})$ ions with the iron oxide loaded riverbed sand have been studied by applying pseudo first-order kinetic and pseudo-second-order kinetics.

\section{Pseudo First-Order Kinetic Model}

The pseudo-first-order kinetic model describes the adsorption of liquid/solid system based on solid capacity. The pseudo first-order rate kinetic model is expressed as follows [14], [15]:

The integrated form of above reaction is as follows:

$$
\log q_{e}=\log \left(q_{t}-q\right)-\frac{k_{1}}{2.303} t
$$

$k_{1}\left(\mathrm{~min}^{-1}\right)$ is the rate constant of first order kinetic equation, $q_{e}$ and $q$ are the amount of $\mathrm{Cr}(\mathrm{VI})$ ions adsorbed at equilibrium and at any time respectively $(\mathrm{mg} / \mathrm{g})$.

The value of $k_{1}$ was determined from slope of the linear plots of $\log \left(q_{e^{-}} q_{t}\right)$ vs $t$ at different temperatures (Fig. 4). Values of pseudo first order rate constant at different temperature is given in Table I.

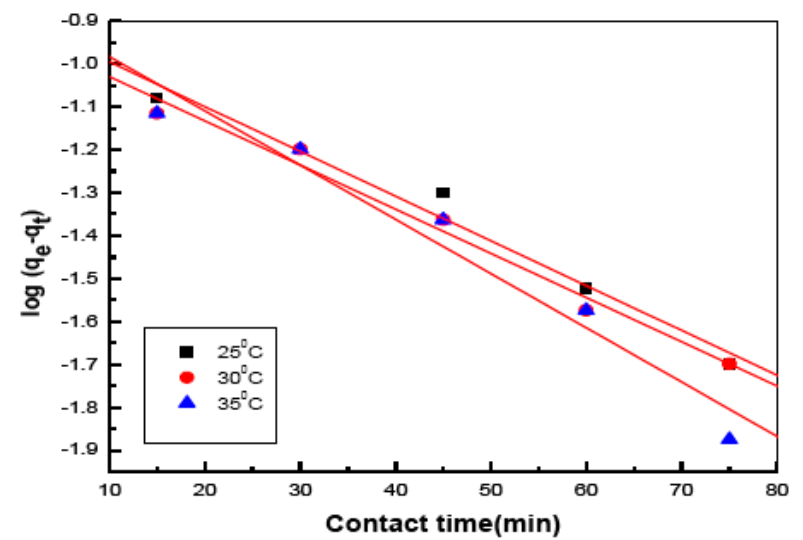

Fig. 4. Pseudo first order kinetic plot for the removal of $\mathrm{Cr}(\mathrm{VI})$ by adsorption on IOLRS.

\section{E. Pseudo-Second-Order Kinetic Model}

According to pseudo-second-order model, the rate limiting step is the chemical sorption which may be due to involvement of valence forces between sorbent and sorbet. This can be expressed as follows [16]:

TABLE I: VALUES OF KINETIC PARAMETERS

\begin{tabular}{ccccc}
\hline Temp. $\left({ }^{\circ} \mathrm{C}\right)$ & $\mathrm{k}_{1}\left(\mathrm{~min}^{-1}\right)$ & $\mathrm{q}_{\mathrm{e}}(\mathrm{Cal})$. & $\mathrm{q}_{\mathrm{e}}($ exp. $)$ & $\mathrm{R}^{2}$ \\
\hline 25 & 2.05 & 0.128 & 0.131 & 0.98 \\
30 & 2.13 & 0.118 & 0.136 & 0.99 \\
35 & 1.97 & 0.139 & 0.143 & 0.97 \\
& & & & \\
& $\mathrm{k} 2$ (g/ mg.min $)$ & $\mathrm{q}_{\mathrm{e}}(\mathrm{Cal})$. & $\mathrm{q}_{\mathrm{e}}(\mathrm{exp})$. & $\mathrm{R}^{2}$ \\
30 & 0.083 & 0.202 & 0.131 & 0.96 \\
35 & 0.131 & 0.187 & 0.136 & 0.97 \\
\hline
\end{tabular}

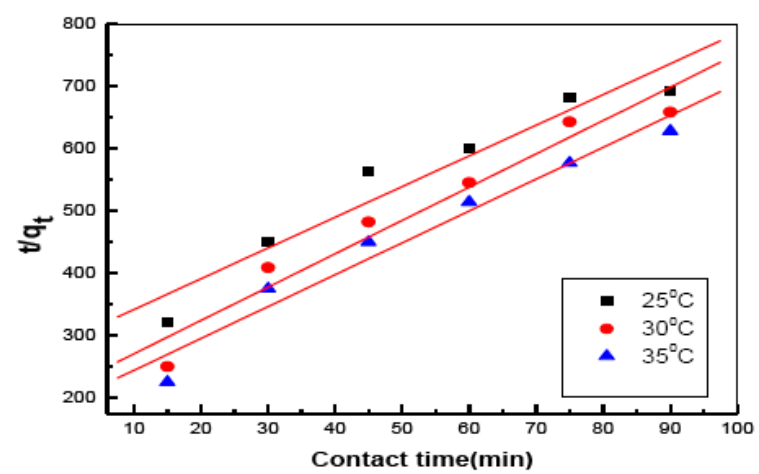

Fig. 5. Pseudo second order plot for the removal of $\mathrm{Cr}(\mathrm{VI})$ by adsorption on IOLRS.

$$
\begin{gathered}
\frac{t}{q_{t}}=\frac{1}{k_{2} q_{e}^{2}}+\frac{1}{q_{e}} t \\
h=k_{2} q_{e}^{2}
\end{gathered}
$$

where $\mathrm{k}_{2}$ (g/mg.min) is the rate constant of pseudo-second order kinetic equation. $\mathrm{h}$ is known as initial sorption rate. The value of $\mathrm{q}_{\mathrm{e}}$ and $\mathrm{k}_{2}$ can be determined by the slope and intercepts of the straight line of the plots' $t / q_{t}$ vs $t$ ', respectively (Fig. 5). It was observed that there is not very much difference in value of $\mathrm{q}_{\mathrm{e}}$ calculated and $\mathrm{q}_{\mathrm{e}}$ experimental for the pseudo first order kinetic model while in case of pseudo second order, there is significant difference in the two values. The experimental $\mathrm{q}_{\mathrm{e}}$ values did not agree with the calculated values obtained from the linear plots. Further, on comparison of value of $\mathrm{R}^{2}$ for both kinetic models, it was found that $R^{2}$ values obtained were lower than that of the pseudo-first -order kinetic model. On the basis of comparison of both models it can be stated that removal of $\mathrm{Cr}(\mathrm{VI})$ was governed by pseudo first order kinetics.

\section{F. Equilibrium Study}

The equilibrium data obtained in the current investigation was examined with Langmuir, Freundlich and Tempkin isotherm models.

\section{G. Langmuir Isotherm}

The Langmuir model assumes that adsorption occurs in a monolayer with all adsorption sites identical and energetically equivalent [16].

The linearized expression of Langmuir model can be 
expressed as follows:

$$
\frac{c_{e}}{q_{e}}=\frac{1}{Q^{o} b}+\frac{c_{e}}{Q^{o}}
$$

where $C_{e}(\mathrm{mg} / \mathrm{L}), q_{\mathrm{e}}(\mathrm{mg} / \mathrm{g})$ are the concentrations of adsorbate and amount of adsorbate adsorbed at equilibrium, respectively. $\mathrm{Q}^{0}(\mathrm{mg} / \mathrm{g})$ and $\mathrm{b}(\mathrm{L} / \mathrm{mg})$ are known as Langmuir's constants which is related to the capacity and energy of adsorption, respectively. The equilibrium data was plotted for ' $C_{\mathrm{e}} / q_{\mathrm{e}}$ vs $C_{\mathrm{e}}$ ' (Fig.6). Values of Langmuir's constant is given in Table II.

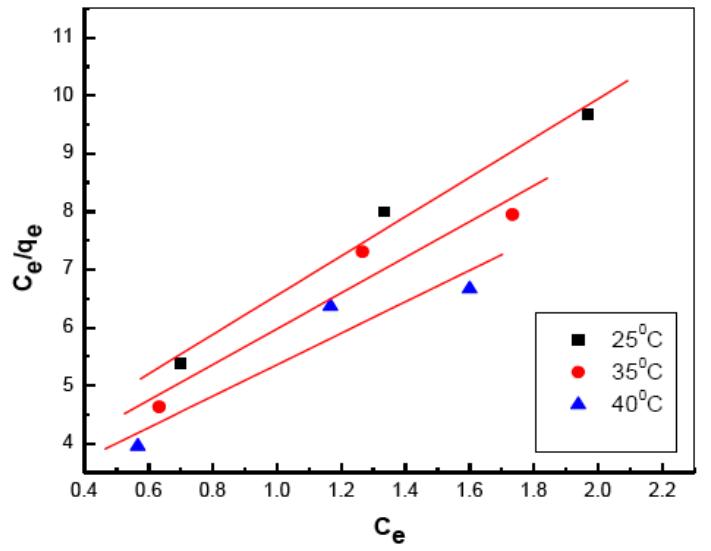

Fig. 6. Langmuir's plot for the removal of $\mathrm{Cr}$ (VI) from aqueous solutions at different temperature.

\section{H. Thermodynamic Study}

Thermodynamic studies always provide vital information for processes including adsorption. Different thermodynamic parameters were viz. standard free energy $\left(\Delta G^{0}\right)$, enthalpy $\left(\Delta \mathrm{H}^{0}\right)$ and entropy $\left(\Delta \mathrm{S}^{0}\right)$ were determined by using the following expressions [17]-[20]:

$$
\begin{gathered}
K_{C}=\frac{C_{A C}}{C_{e}} \\
\Delta \mathrm{G}^{\circ}=-\mathrm{RT} \ln \mathrm{Kc} \\
\Delta \mathrm{H}^{\mathrm{O}}=\mathrm{R}\left(\frac{\mathrm{T}_{2} \mathrm{~T}_{1}}{\mathrm{~T}_{2}-\mathrm{T}_{1}}\right) \ln \left(\frac{\mathrm{K}_{\mathrm{c} 2}}{\mathrm{~K}_{\mathrm{c} 1}}\right) \\
\Delta \mathrm{S}^{\mathrm{O}}=\frac{\left(\Delta \mathrm{H}^{\mathrm{O}}-\Delta \mathrm{G}^{\mathrm{O}}\right)}{\mathrm{T}}
\end{gathered}
$$

TABLE II: ISOTHERM PARAMETERS FOR THE SYSTEM

\begin{tabular}{lllll}
\hline & $\begin{array}{l}\text { Temp. } \\
\left({ }^{0} \mathrm{C}\right)\end{array}$ & $\mathrm{Q}^{0}(\mathrm{mg} / \mathrm{g})$ & $\mathrm{b}(\mathrm{L} / \mathrm{mg})$ & $\mathrm{R}^{2}$ \\
\hline Langmuir's & 25 & 0.295 & 1.07 & 0.99 \\
parameters & 30 & 0.325 & 1.06 & 0.96 \\
& 35 & 0.369 & 1.02 & 0.94 \\
Freundlich's & 25 & $\mathrm{~K}_{\mathrm{f}}(\mathrm{mg} / \mathrm{g})$ & $\mathrm{n}$ & $\mathrm{R}^{2}$ \\
parameters & 30 & 0.150 & 2.335 & 0.99 \\
\hline
\end{tabular}

where $\mathrm{K}_{\mathrm{c}}$ is the equilibrium constant, $\mathrm{C}_{\mathrm{Ac}}$ and $\mathrm{C}_{\mathrm{e}}$ (both is in $\mathrm{mg} / \mathrm{L}$ ) are equilibrium concentration for solute on the sorbent and in the solution respectively. $\mathrm{R}$ is the universal gas constant (1.987cal/mol.K) and $\mathrm{T}(\mathrm{K})$ is the absolute temperature. Values of different thermodynamic parameters calculated from above equations are given in Table III. The values of $\Delta G^{0}$ were found to be negative at all temperature which confirms the feasibility of the process and the spontaneous nature of adsorption.

Value of $\Delta \mathrm{G}^{0}$ increase by increasing temperature it showed that the adsorption is favorable at higher temperatures. The positive value of $\Delta \mathrm{H}^{0}$ indicates endothermic nature of removal process. The positive value of $\Delta \mathrm{S}^{0}$ suggests increase randomness at the solid-liquid interface during adsorption.

TABLE III: VALUES OF DIFFERENT THERMODYNAMIC PARAMETERS FOR REMOVAL OF CR(VI) BY IOLRS

\begin{tabular}{lccl}
\hline \multicolumn{4}{c}{ Thermodynamic parameters } \\
\hline Temp $\left({ }^{\circ} \mathrm{C}\right)$ & $\begin{array}{c}\Delta \mathrm{G}^{0} \\
(\mathrm{kcal} / \mathrm{mol})\end{array}$ & $\begin{array}{c}\Delta \mathrm{H}^{0} \\
(\mathrm{kcal} / \mathrm{mol})\end{array}$ & $\begin{array}{l}\Delta \mathrm{S}^{0} \\
(\mathrm{cal} / \mathrm{mol} . \mathrm{K})\end{array}$ \\
25 & -0.37 & +7.79 & +24.91 \\
30 & -0.46 & & \\
35 & -0.57 & & \\
\hline
\end{tabular}

\section{Desorption Studies}

Desorption studies help to determine the adsorption mechanism involved in any system and to evaluate the feasibility of regenerating the exhausted adsorbent. After completion of adsorption process, the adsorbent used for removal of pollutants cannot be disposed in its final form because the pollutant species can leach into ground water which is undesirable from environmental point of view. The results of the desorption experiments are depicted in Fig. 7. According to the results of desorption studies (Fig. 7), the amount of desorbed $\mathrm{Cr}(\mathrm{VI})$ increased with the increase of $\mathrm{pH}$. It is clear that only $10 \%$ desorption rate can be achieved at $\mathrm{pH}$ 4 while by increasing $\mathrm{pH}$ from 4 to 12 , rate of desorption increased up to $89 \%$.

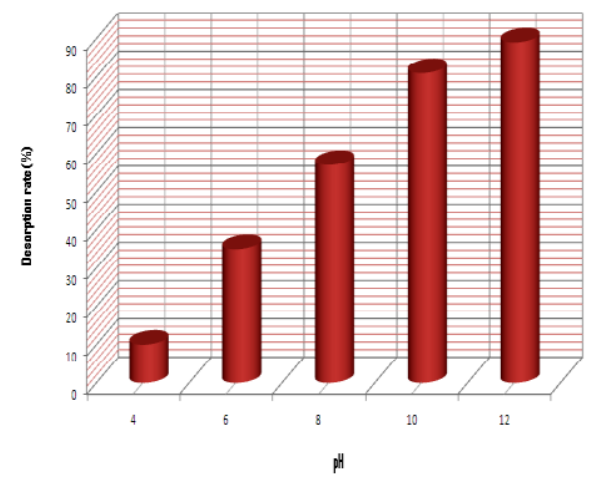

Fig. 7. Desorption studies of $\mathrm{Cr}(\mathrm{VI})$ from IOLRS

\section{CONCLUSIONS}

Adsorption of hexavalent chromium on Iron oxide loaded riverbed sand (IOLRS) has been studied. Adsorbent material was prepared using a simple process of precipitation of iron oxide on riverbed sand. It was found that initial concentration plays an important role in removal process. Removal was higher at lower initial concentration. $\mathrm{pH}$ study shows that higher removal can be obtained by maintaining the solution $\mathrm{pH}$ in acidic range. Removal of $\mathrm{Cr}(\mathrm{VI})$ was higher at higher temperature indicating endothermic nature of process. On analyzing the resultant data by pseudo-first order and pseudo 
second order kinetic models, it was observed that removal of Cr(VI) was governed by pseudo-first order kinetics. Adsorption capacity of adsorbent increases by increasing temperature which confirms the endothermic nature of adsorption process. Studies of various thermodynamic parameters indicate the feasibility, endothermic nature and spontaneity of removal process of $\mathrm{Cr}(\mathrm{VI})$ by adsorption. Further, the synthesis method used for the preparation of Iron oxide loaded riverbed sand (IOLRS) is not very costly and synthesized adsorbent has potential for the removal of $\mathrm{Cr}(\mathrm{VI})$ from aqueous solutions it can be proved an economically viable alternate for costly adsorbent.

\section{ACKNOWLEDGEMENTS}

The authors are thankful to DRDO, Govt of India for granting research project (P31/46).

\section{REFERENCES}

[1] B. Albadarin et al., "Kinetic and thermodynamics of chromium ions adsorption onto low-cost dolomite adsorbent," Chem.Eng. J., vol. 179, pp. 193-202.

[2] N. Ballav et al., "High efficient removal of chromium(VI) using glycine doped polypyrroleadsorbent from aqueous solution," Chem. Eng. J., vol. 198, pp. 536-546, 2012.

[3] M. Jain et al., "Chromium(VI) removal from aqueous system using Helianthus annuus (sunflower) stem waste," J. Hazard. Mater, vol. 162, 365-372, 2009.

[4] E. Finocchio et al., "Chromium (VI) removal by methylated biomass of Spirulina platensis: The effect of methylation process," Chem. Eng. J., vol. 156, pp. 264-269, 2010.

[5] X. W. Wu et al., "Adsorption of chromium(VI) from aqueous solution by a mesoporous aluminosilicatesynthesized from microcline," Appl. Clay Sci., vol. 48, pp. 538-541, 2010.

[6] S. Chen et al., "Adsorption of hexavalent chromium from aqueous solution by modified cornstalk: A fixed-bed column study," Bioresour. Technol., vol. 113, pp. 114-120, 2012.

[7] Y. C. Sharma et al., "Synthesis and applicationof nano- $\mathrm{Al}_{2} \mathrm{O}_{3}$ powder for the reclamation of hexavalentchromium from aqueous solutions," $J$ Chem. Eng. Data, vol. 552, pp. 390-2398, 2010.

[8] J. Zolgharnein et al., "Adsorption of $\mathrm{Cr}(\mathrm{VI})$ onto elaeagnus tree leaves: Statistical optimization, equilibrium modeling and kinetic studies," $J$. Chem. Eng. Data, vol. 55, pp. 3428-3437, 2010.

[9] S. Basha et al., "Biosorption of hexavalent chromium by chemically modified seaweed, Cystoseira indica," Chem. Eng. J., vol. 137, pp. 480-488, 2008.

[10] W. Li et al., "Removal of Cr(VI) from low-temperature micro-polluted surface water by tannic acid immobilized powdered activated carbon,' Bioresour. Technol., vol. 113, pp. 106-113, 2012.

[11] WHO, Guidelines for Drinking Water Quality, vol. 1, 1993, World Health Organization.

[12] X. Jing et al., "Biosorption of Cr(VI) from simulated wastewater using a cationic surfactant modified spent mushroom," Desalination, vol. 269, pp. 120-122, 2011.

[13] V. S. Mane et al., "Studies on the adsorption of Brilliant Green dye from aqueous solution onto low-cost $\mathrm{NaOH}$ treated saw dust," Desalination, vol. 273, pp. 321-329, 2011.

[14] T. Karthikeyan et al., "Chromium (VI) adsorption from aqueous solution by Hevea Brasilinesis sawdust activated carbon," J. Hazard. Mater., vol. B12, pp. 192-199, 2005.

[15] K. Y. Foo et al., "Insights into the modeling of adsorption isotherm systems," Chem. Eng. J., vol. 156, pp. 2-10, 2010.

[16] V. Ramasamy et al., "Effect of grinding on the crystal structure of recently excavated dolomite," Ind. J. Pure \& Appl. Phy., vol. 47, 586-591, 2009.

[17] S. Yadav et al., "Studies on the removal of $\mathrm{Ni}(\mathrm{II})$ from aqueous solutions using modified riverbed sand environ," Sci. Pollut. Res., 2012.

[18] R. Huang et al., "Equilibrium, kinetic and thermodynamic studies of adsorption of $\mathrm{Cd}(\mathrm{II})$ from aqueous solution onto HACC-bentonite,' Desalination, vol. 280, pp. 297-304, 2011.

[19] W. Rudzinski et al., "Kinetics of solute adsorption at solid/solution interfaces: A theoretical development of the empirical pseudo-first and pseudo second order kinetic rate equations, based on applying the statistical rate theory of interfacial transport," J. Phys. Chem. B, vol. 110, p. 16514,2006

[20] Y. Wang et al., "Cr(VI) removal from water using cobalt-coated bamboo charcoal prepared with microwave heating," Ind. Crops Prod., vol. 39, pp. 81-88, 2012.

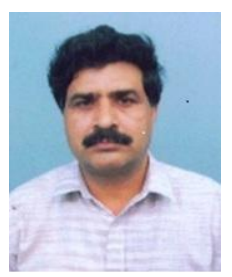

Yogesh C. Sharma is a professor of chemistry. He graduated (Ph.D.) from Institute of Technology, Banaras Hindu University, Varanasi, India in 1991 and obtained the doctor of science (D.Sc.) in chemistry from CCS University, Meerut, India in 2010. His research interests are synthesis and characterization of nanoadsorbents, and their application for water remediation. He has extensively worked and published on various aspects of water remediation. He has used waste materials, minerals, marophytes, and activated carbons for removal of metallic pollutants, including arsenic and mercury from water and wastewater. $\mathrm{He}$ also has worked on synthesis of inorganic adsorptive media for removal of fluorides and nitrates from drinking water. Current research interests of Prof Sharma are on Bioenergy and Biofuels. His main focus is on synthesis and characterization of biodiesel, bio oils, and catalysts for biodiesel synthesis. Prof Sharma has a good publication record and has an h index of 40 and more than 6000 citations.

He graduated (Ph.D.) from Institute of Technology, Banaras Hindu University, Varanasi, India in 1991 and obtained Doctor of Science (D.Sc.) in Chemistry from CCS University, Meerut, India in 2010. His research interests are synthesis and characterization of nanoadsorbents, and their application for water remediation. He has extensively worked and published on various aspects of water remediation. He has used waste materials, minerals, marophytes, and activated carbons for removal of metallic pollutants, including arsenic and mercury from water and wastewater. $\mathrm{He}$ also has worked on synthesis of inorganic adsorptive media for removal of fluorides and nitrates from drinking water. Current research interests of Prof. Sharma are on Bioenergy and Biofuels. His main focus is on synthesis and characterization of biodiesel, bio oils, and catalysts for biodiesel synthesis. Prof Sharma has a good publication record and has an h index of 40 and more than 6000 citations.

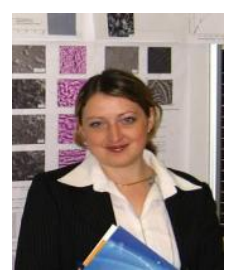

Sofia Yarusova was born on March 10, 1983 in Dalnegorsk (Russia). In 2000 she has graduated (with silver medal) from high school № 1 of Dalnegorsk. In 2005 she has graduated with honors the Vladivostok State University of Economics and Service (VSUES) on specialty "Ecology". From 2005 to 2008 she was studied at the postgraduate school of the Institute of Chemistry, Far-Eastern Branch of Russian Academy of Sciences on specialty "Physical Chemistry" and worked at the position of a junior research fellow in the laboratory of protective coatings and sea corrosion. In $2010 \mathrm{~S}$. Yarusova defended the thesis "Synthesis of calcium silicates in multicomponent systems and their physical and chemical properties" for the Ph.D. degree.

Sofia Yarusova was born on March 10, 1983 in Dalnegorsk (Russia). In 2000 she has graduated (with silver medal) from high school № 1 of Dalnegorsk. In 2005 she has graduated with honors the Vladivostok State University of Economics and Service (VSUES) on specialty "Ecology". From 2005 to 2008 she was studied at the postgraduate school of the Institute of Chemistry, Far-Eastern Branch of Russian Academy of Sciences on specialty "Physical Chemistry" and worked at the position of a junior research fellow in the laboratory of protective coatings and sea corrosion. In 2010 S. Yarusova defended the thesis "Synthesis of calcium silicates in multicomponent systems and their physical and chemical properties" for the Ph.D. degree.

Since 2011 to the present time she is a research fellow of the laboratory of protective coatings and sea corrosion of the Institute of Chemistry, Far-Eastern Branch of Russian Academy of Sciences. Since 2015 she is the head of the Department of ecology and environmental problems of chemical technology of the VSUES. She is author of more than 100 scientific papers, 10 patents and also a coauthor of two monographs. Research interests: ecology, environment, complex processing of mineral raw materials and industrial waste, obtaining silicate materials (calcium hydrosilicates and wollastonite) for the construction industry and promising sorbents for the purification of aqueous solutions from ions of heavy metals and radionuclides.

S. Yarusova is a member of the Russian Chemical Society named after D.I. Mendeleev (since 2010), corresponding member of the Russian Ecological Academy (since 2011) and also a member of the editorial board of the "Environmental Chemistry" journal. 